\title{
Para Onde Caminha a Disciplina de Organização, Sistemas e Métodos nos Cursos de Administração: uma Análise Documental
}

\author{
Andreza Raquel Campos Barros ${ }^{1}$; Alyne Leite de Oliveira, ${ }^{2}$ Antonio Raniel Silva Lima ${ }^{3}$
}

Resumo: O objetivo geral dessa pesquisa é verificar como as universidades trabalham a disciplina de OSM no curso de Administração. Esta pesquisa é tem um caráter exploratório, visto que são mínimos os trabalhos que abordam esta problemática. Trata-se de uma pesquisa de abordagem qualitativa. No que se refere ao tipo de estudo, esta pesquisa é caracterizada como uma pesquisa documental. Para o alcance do objetivo desta pesquisa, foram selecionadas 20 Instituições de Ensino Superior (IES) mais bem ranqueadas na edição de 2015 do ENADE do curso de Administração. Os dados foram coletados no website das IES e a análise dos resultados utilizou critérios da análise do conteúdo. De acordo com a busca pelas ementas da disciplina de OSM, foi possível constatar que ainda se trabalha a disciplina com essa nomenclatura, também se observou em outros casos que a disciplina é trabalhada com outro título, o que pode apontar para onde se encaminha OSM, em poucos casos não se trabalha OSM.

Palavras-chave: Organização. Sistemas. Métodos.

\section{Where to Walk the Discipline of Organization, Systems and Methods in the Administration Courses: A Documentary Analysis}

\begin{abstract}
The general concept of this research is to verify how the basic areas of study of the OSM in the course of Administration. This research is of an exploratory type, since it is of little value for the works that approach this problematic. This is a qualitative approach research. Regarding the type of study, this research is characterized as a documentary research. In order to reach this research, the 20 higher education institutions (IES) that were ranked the highest in the 2015 edition of the ENADE Management course were selected. The data were collected on the HEIs website and an analysis of the results using content analysis. According to an idea of the OSM, it was possible to verify that there is still a task with this nomenclature, also in other cases that a code is worked with that title, that can point to the routing of the OSM, in few cases it does not work OSM.
\end{abstract}

Keywords: Organization. Systems. Methods.

\footnotetext{
${ }^{1}$ Graduanda do curso de Administração do Centro Universitário Doutor Leão Sampaio/Unileão.

Contato: andrezaarcb@gmail.com

${ }^{2}$ Professora Orientadora do Centro Universitário Doutor Leão Sampaio/Unileão. Contato:

alyneoliveira@leaosampaio.edu.br.

${ }^{3}$ Professor co-orientador do Centro Universitário Dr. Leão Sampaio/UniLeão e da Faculdade Vale do Salgado/FVS. Contato: raniel@leaosampaio.edu.br.
} 


\section{Introdução}

Observa-se que com as novas exigências que o mercado apresenta diariamente, faz-se necessário que os profissionais aprofundem seus conhecimentos e sigam essas mudanças independente de sua formação acadêmica (OLIVEIRA et al., 2012).

O estudo da Administração e a tecnologia de ponta fazem uma junção explosiva, que contribuirá para o desenvolvimento de nossa sociedade (CORREIA, 2009). O curso abrange inúmeras disciplinas que favorecem para o embasamento da construção do profissional, algumas disciplinas ganham destaque.

Organizações de Sistemas e Métodos (OSM) é uma das disciplinas que se destacam composta por sua ampla e inúmeras linhas de pensamento, que vinculam esta disciplina à Tecnologia de Informações, aos Métodos Produtivos, às Medidas de Desempenho, ao Desenvolvimento Organizacional e ao Controle de Processos Produtivos e Empresariais (SANTOS, 2012).

Considerando as questões de relevante influência teórica respectiva às principais noções da ciência administrativa, onde está área é classificada de suma importância através do seu complexo significado de definições, explanação e elucidação que proporciona ao acadêmico.

Os paradigmas inseridos no campo do desenvolvimento acadêmico no que se refere às atuais abordagens elaboradas e atualizadas conduzidas no processo de ensino-aprendizado na conjuntura das instituições de ensino superior, especialmente na linha de OSM.

Partindo desse contexto acima tem-se a seguinte pergunta de partida. Como são abordadas as temáticas dessa disciplina nas instituições de ensino superior e quais suas perspectivas futuras no contexto acadêmico?

Logo, o objetivo geral dessa pesquisa é verificar como as universidades trabalham a disciplina de OSM no curso de Administração. Tem-se como objetivos específicos: i) analisar a área de OSM dentro do contexto organizacional; ii) verificar os principais assuntos abordados na área de OSM no curso de Administração; e iii) analisar as emendas dos cursos de Administração de instituições de nível superior.

Diante da importância da disciplina para o curso de Administração e para o embasamento analítico, tornou-se relevante ampliar o conhecimento sobre a área pesquisada podendo verificar e acompanhar como é feita a abordagem da área de OSM, verificar sua importância e quais as principais abordagens que as universidades focam de acordo com os princípios da Administração. 
A percepção do comportamento da disciplina de OSM pode ajudar a futuros pesquisadores do assunto, a entender a linha de ensino que está sendo adotado, com fundamento na análise da ementa da disciplina. A pesquisa pode ajudar a servir como base para coordenadores de curso e de instituições que tem como objetivo transmitir o conhecimento de OSM.

\section{Referencial Teórico}

\section{O Ensino no Brasil e as Instituições de Ensino Superior}

Segundo o MEC, o ensino superior tem por função incentivar o desenvolvimento cultural e a evolução do espírito científico e do pensamento reflexivo, construir diplomados nas diferenciadas áreas de estudo, capacitando o acadêmico para a inclusão em setores profissionais e para a atribuição no crescimento da sociedade brasileira, auxiliar na sua formação contínua.

Compreende também o estímulo para a compreensão dos problemas do mundo contemporâneo, sobretudo problemas regionais, fornecer serviços preparados a comunidade e introduzir com essa uma relação mutua. Compõe também o Art. 45. "A educação superior será ministradas em instituições de ensino superior, públicas ou privadas, com variados graus de abrangência ou especialização". (BRASIL, 1996)

Neves (2002) retrata opinião que coincide com o MEC onde cita que a educação superior no Brasil engloba, atualmente, um sistema complexo e diversificado de instituições públicas e privadas com diversos tipos de cursos e projetos, abrangendo diferentes níveis de ensino, desde a graduação até a pós-graduação. A padronização atual desse extenso sistema encontra-se formalizada na Constituição, bem como na LDBN/96, acrescentada de um amplo grupo de Decretos, Regulamentos e Portarias complementares.

O ensino superior no Brasil tem sofrido considerações reflexivas de diversas frentes e dimensões, o que acarreta a inevitabilidade de discussão sobre a renovação conceitual, política e pedagógica dos planos educacionais demonstrados nos projetos político-pedagógicos das Instituições de Ensino Superior (IES) que tratam com a construção de nível superior (SANTOS 2010).

Para Abdo (2012), as técnicas e estratégias que os professores se apoiaram antigamente, parece não funcionar atualmente. É necessário que se reconsidere os projetos pedagógicos, as 
visões e especialmente as metodologias de ensino, visto que os estudantes estão aprendendo a interagir de uma maneira nova.

Diante do estabelecido, compete a cada instituição indagar e reorientar o método formativo de seus cursos, adequando-os às novas necessidades sociais, a partir de um debate que começa pelo perfil aguardado do egresso e pela definição de quais serão os procedimentos pedagógicas a serem aplicadas para garantir uma formação conduzida para os princípios estabelecidos por esta realidade (SANTOS, 2010).

\section{A Aplicabilidade do Ensino na Área de Gestão}

A elaboração do projeto político-pedagógico é um desafio permanente para a escola, aqui entendida como a entidade responsável pelo projeto e propagação do saber em qualquer grau de ensino. Este desafio torna-se amplo se pensarmos em aplicar esta ferramenta de trabalho a propriedade 'mágica' de solucionar os mais diferentes problemas demonstrados pelas escolas, sobremaneira as públicas, a fim de lidar com as demandas emergentes da difícil tarefa de educar (SANTOS, 2010).

Oliveira et al. (2012) considera que, independentemente da formação acadêmica dos profissionais da época atual, suas competências profissionais devem seguir as mudanças que ocorrem à sua volta como também as novas vertentes globais. Siqueira (2011) aponta que a afinidade de todo o modelo educacional contemporâneo, o ensino e a execução da administração e da gestão das empresas é fundamentada nos pressupostos de um corpo social inteiramente inserido no mercado.

No decorrer do curso de Administração são exibidas várias disciplinas que colaboram para a construção dos profissionais, construção esta, que possui algumas metas a serem alcançadas, algumas destas disciplinas alcançam destaque segundo o seu grau de importância e atuação no alcance do objetivo traçado. Seguramente a relevância de uma disciplina só será estimada pelos estudantes quando na execução puderem constar que o uso daquele conhecimento se fez útil em determinado momento (ABDO, 2012).

Além destes aspectos, é uma apreensão da comunidade acadêmica o acréscimo de valores morais e éticos, como condição de fomentar os comportamentos e atitudes adaptáveis com as condições dos atuais ambientes de relacionamento. Entende-se que sejam necessárias diretrizes que incentivem o uso de metodologias que consistam na vivência de situações práticas como demonstração da vida real (SANTOS, 2012). 
Tais vivências proporcionariam a passagem de uma compreensão de desenvolvimento cognitivo para avanços comportamentais dos alunos em relação às questões debatidas no momento presente do ambiente empresarial, que são as práticas acordadas pelo modelo de excelência em gestão, tais como: "liderança, estratégias e planos, clientes, sociedade, informação e conhecimento, pessoas e processos". (SANTOS, 2012, p. 68).

Por fim, o ensino de Administração deve ser canalizado para a preparação dos acadêmicos para os fenômenos que irão deparar-se nas organizações ou para introduzir as ferramentas e funções que serão solicitadas a dominar como administrador. Se obtivermos essa premissa, o ensino de administração precisaria, necessariamente, guardar relação com os fenômenos encontrados na realidade empresarial e com as ferramentas e funções de fato utilizados no dia-a-dia das empresas (CALDAS, 1998).

\section{Organizações, Sistemas e Métodos}

Durante muitos anos escutava-se falar a expressão O \& M (Organização e Método), sem saber ao certo o que representava. Caracterizava pela necessidade de organizar uma empresa com a direção de métodos de trabalho, observação e a uniformização destes métodos. Vários tinham o pensamento voltado que $\mathrm{O} \& \mathrm{M}$ era um quadro com a representação da estrutura organizacional da empresa onde nem sempre era a empresa em questão (CURY, 2006).

Cruz (2013) cita os mesmos itens apresentado por Cury (2006) e acrescenta que como a todo tempo foi famosa em propriedades, permaneceu a muito tempo como sendo o princípio de ideias de racionalização inseridas em qualquer corporação. Essa era a sua particularidade sem ser subordinada a hierarquia que houvesse na estrutura.

Já Cardoso (2014) posteriormente relata que com o surgimento da informática, um novo elemento associado passou a fazer parte das atribuições do novo conceito de organização: o sistema. Onde passou a ser chamado de Organização, Sistemas e Método. Nas empresas de grandes níveis criou-se uma unidade para o desenvolvimento do sistema e outro voltado para organização e métodos $(\mathrm{O} \& \mathrm{M})$, nessa unidade eram feitos a sondagem das questões indispensáveis das empresas para serem otimizadas pelo pessoal do sistema.

Oliveira (2006) descreve OSM como sendo um método para lidar com o grande e complicado conjunto de serviços da empresa com enfoque exclusivo do todo, que não permite a verificação distinta das partes do todo, em virtude da profunda correlação das partes entre si e com o todo. 
Também sendo um estudo das relações entre os princípios componentes dos sistemas, em prioridade ao estudo isolado dos elementos, exaltando o processo e as possibilidades de mudança especificados em colocação de seus arranjos estruturais e da aplicação de ação destes elementos (OLIVEIRA, 2006).

Santos (2012) expõem que Organização, Sistemas e Métodos é muito amplo e com inúmeras linhas de pensamento, que vinculam esta disciplina à Tecnologia de Informações, aos Métodos Produtivos, às Medidas de Desempenho ao Desenvolvimento Organizacional, e ao Controle de Processos Produtivos e Empresariais.

\section{Atividades da Área de OSM}

A função da área de OSM era direcionada "para o desenvolvimento de um sistema entre quatro paredes" para os diversos subsistemas da empresa, onde era necessária a prática (CARDOSO, 2014, p. 2). Uma das ferramentas de análise de OSM é a análise organizacional que permite aos gestores um estudo profundo que proporcionará uma visão coerente sobre a organização e em efeito a isso uma melhoria constante nos processos organizacionais (CURY, 2006).

Numa visão estratégica, Llatas (2012 apud SILVA; SILVA, 2016) refere-se que essa abordagem em uma organização ajuda a distinguir os métodos mais eficientes, o que ocasiona no descarte do gasto do tempo, material e esforço, modificando as ideias em planos, incluindo a verificação e certificar no tempo certo as falhas dos objetivos traçados.

Cardoso (2014) inclui que o objetivo é desenvolver ou aprimorar técnicas de trabalho, otimização do processo, excluir tarefas em duplicidade, uniformizar, aperfeiçoar o controle, coordenar os processos e solucionar os problemas.

Cury (2006) acrescenta que essas avaliações fazem parte das ferramentas de OSM para aperfeiçoamento organizacional com foco na qualidade de gestão de processos, pois seus materiais colaboram para o desenvolvimento de novas estratégias que avigoram a estrutura empresarial, introduzindo novas táticas que possibilitem o aumento da produtividade e eficiência das tarefas administrativas.

Como a sua aplicabilidade se faz responsável pela modelagem da empresa, envolvendo, primariamente, a construção de uma infraestrutura conciliável com os propósitos do empreendimento e, auxiliarmente, a definição e/ou redefinição das práticas e métodos de trabalho, mecanizados ou não, fundamentais à efetividade organizacional. Desta forma, tem 
como objetivo final a atualização organizacional, por meio do manuseamento da empresa como um sistema social, aberto, em constante sintonia com as exigências de seu ambiente, externo e/ou interno (CURY, 2017).

\section{O Que Área de OSM Trabalha Hoje}

A disciplina traz para o acadêmico grande embasamento com critérios para a evolução de um trabalho distinto dentro de uma organização, bem como o desenvolvimento e gerenciamento de sua própria empresa (RETIZ, 2014). Visto que é importante que os gestores considerem as atividades de sistemas, organização e métodos como um mecanismo facilitador do processo decisório, da mesma maneira que a operacionalização das definições tomadas e do controle e análise dos resultados obtidos. (OLIVEIRA, 2013)

Cruz (2013) faz alusão de temas acerca de como tudo começou na Administração relatando fatos do início da pré-história com as divisões dos processos de trabalho, trazendo importância para a revolução industrial como um marco na história da humanidade, onde antes tudo era produzido por mestres de cada especialidade e artesões dominando o processo primário de construção, com a revolução veio a substituição desses processos primários pela energia a vapor que conseguia criar e movimentar grandes maquinas.

Vinculando a isso, Cruz (2013) aborda assuntos da Escola Clássica da Administração dando destaque a Taylor e Fayol com o desenvolvimento da Administração Científica. Partindo para a evolução com as estruturas formais e informais e seus relacionamentos, organização em linha, funcional e assessoria, departamentalização, sistemas e informação e informações estratégicas (CRUZ, 2013).

Oliveira (2013) relata de forma sistemática em seus livros aspecto que reforçam a validade do desenvolvimento dentro de uma abordagem gerencial, abordando temas como aspectos básicos sobre os sistemas administrativos, pontos dos sistemas administrativos direcionados para o processo decisório, explana, com coerente profundidade, um modelo de desenvolvimento e prática da estrutura organizacional nas empresas.

Examina, com detalhes, os tipos, atributos, vantagens e atenções no uso das diversas formas de departamentalização da estrutura organizacional nas organizações. Exibe os dados básicos de utilização das unidades organizacionais dos traços de assessoria, principais características da delegação, da descentralização e da centralização nas empresas, com suas características, diferenças, vantagens e cautelas em seu uso e discute com o grau de detalhe 
necessário os vários níveis de hierarquia e amplitude de controle das unidades organizacionais (OLIVEIRA, 2013).

Fica convincente a importância de OSM com relevância para vida acadêmica com construção de um profissional analítico, organizado, com desejo de mudança e quebra de paradigmas. Auxiliando na geração de um indivíduo comprometido com as pessoas, estas que movem e enriquecem as organizações, "desejo de aprimorar, racionalizar e contribuir para o desenvolvimento organizacional”. (RETIZ, 2014, p. 1).

\section{Pespectivas Para a Área de OSM}

O\&M não é facilmente encontrada em organizações. Supostamente, muitas das associações e congressos não são numerosos como antes. Nota-se também que não encontramos com facilidade o departamento dessa área em estruturas organizacionais, diferente do que ocorria outrora (CALDAS 1999).

Oliveira et al. (2012) esclarecem que precisamos manter uma junção de parâmetros para que outro institucionalíssimo nos possibilite, também considerar aspectos cognitivos e comportamentais, orientadas por canais que conseguiram auxiliar em uma releitura dos novos paradigmas que nos cerca. Além de que essa direção simplifica uma análise de interdependência, alguns caminhos teóricos estão em destinos divergentes, quando relacionado ao isomorfismo.

Caldas (1999) relata que a validação da cadeira de OSM dentro da grade curricular do curso de Administração parece indicar para uma hipótese implícita na academia de que sua função teria sofrido poucas alterações, e de que sua natureza não só está permanente na realidade, como seu ensino é fundamental para a formação de todo administrador.

Se alguma pesquisa empírica pesquisar o conteúdo programático da cadeira obrigatória, possivelmente deparar-se-á com sinais da concretização dessa premissa de imutabilidade, mencionada pelo ensino. Evidentemente que não em todos, mas em grande parte significativa dos cursos de Administração no Brasil (CALDAS, 1999). 


\section{Para Onde se Encaminha OSM}

No contexto organizacional, O O\&M (Organização e Métodos) ou S\&M (Sistemas e Métodos) passou a exercer em muitas empresas um papel proativo, encontrando um cenário aberto para execução de melhorias e mediando nas funções dos colaboradores mesmo quando não era solicitado (CALDAS, 1999).

Já Oliveira (2013) indica que essa prática simplista terá que evoluir nas organizações, pois a realidade das empresas necessita de novas habilidades profissionais, para que possa tornar eficientes seus processos e consequentemente contribuir para evolução organizacional.

$\mathrm{Na}$ atualidade, investiga-se o homem como elemento primordial do processo, analisa-se o comportamento das operações e o do indivíduo. De tal forma que os processos de trabalho deixam de ter um caminho fechado e passam a ser orientados. Estabelecendo espaço à criatividade e para propósitos desafiadores, utilizando essas ferramentas motivacionais para o alcance das metas da organização, conivente ao desenvolvimento particular e profissional dos colaboradores (CARDOSO, 2014).

Oliveira (2013) enumera algumas habilidades, como habilidade técnica que equivale em fazer uso do conhecimento, lógica e estratégica com utilização de materiais indispensáveis para a execução de atividades exclusivas, a partir de conhecimento que os pesquisadores da área precisam apresentar, havendo em vista o aprimoramento das relutâncias dos processos.

As estruturas operacionais e organizacionais das instituições determinadas no século passado não utilizam de avanços que o mercado exige. $\mathrm{O}$ estudo da administração e a tecnologia de ponta fazem uma junção explosiva, onde contribuirá para o desenvolvimento da sociedade. Não resta dúvida de que o cenário mundial é de amplas transformações no cenário econômico, político e social, visto que são resultados empresarias decorrente da atuação dos administradores (CORREIRA, 2009).

\section{A Importância da OSM para o Profissional de Gestão}

Retiz (2014) menciona que essa área atribui para o discente um princípio amplo de fundamentos com domínio para o desenvolvimento de trabalho exclusivo, incluso na organização, contribuindo para sua permanência no mercado diante da competição globalizada, proporcionando para ele a possibilidade de desenvolver o controle adequado para sua própria 
empresa. Onde muitas das empresas que não fazem uso dos métodos práticos dessa área deixam de existir.

Oliveira et al. (2012) citam que esse tema se faz relevante para o gestor, pois possibilita a ele um olhar crítico de diagnosticar a origem dos problemas e seus mecanismos de trabalho, solucionando-os de maneira adequada com aplicação de ferramentas corretas.

Já Abdo (2012) afirma que está é uma ferramenta crucial para um bom desempenho profissional e com certeza, se operada de modo exato, é motivo decisivo para uma organização manter-se em um ótimo grau de relevância comparada com as outras.

\section{Métodologia}

No que se refere ao objetivo, esta pesquisa é tem um caráter exploratório, visto que são mínimos os trabalhos que abordam esta problemática. Com relação à abordagem, trata-se de uma pesquisa de abordagem qualitativa. Segundo Silva (2008), a pesquisa qualitativa é utilizada quando o pesquisador encontra fatos em ponto de complexidade, que tornam difícil a quantificação. No que se refere ao tipo de estudo, esta pesquisa é caracterizada como uma pesquisa documental.

Para o alcance do objetivo desta pesquisa, foram selecionadas 20 Instituições de Ensino Superior (IES). Esta escolha se deu de acordo com a nota do curso de Administração de cada IES no Exame Nacional de Desempenho de Estudantes (ENADE) do ano de 2015.

O ENADE tem uma periodicidade trienal, assim, as últimas notas publicadas no portal de Inep são do ano de 2015. Vale ressaltar que as IES que tiveram um quantitativo menor que 10 alunos que fizeram a prova na edição de 2015, foram excluídas, sendo adicionada a próxima IES mais bem ranqueada.

Os dados foram coletados no website das IES, a análise dos resultados utilizou critérios da análise do conteúdo e os resultados são apresentados a seguir.

\section{Análise e Discussão dos Resultados}

Para a construção da análise foram levantadas informações através do PPC Projeto Pedagógico do Curso (PPC) e das ementas que eram disponibilizadas diretamente no site de 20 IES com melhores notas no ENADE no ano de 2015. 
Das 20 IES investigadas, como mostra o Gráfico 01, apenas sete ainda trabalham OSM com o mesmo nome. Em três IES foram encontradas a disciplina de Administração de Sistemas de Informação, dentre elas apenas duas disponibilizam a ementa, uma trata de assuntos que se assemelha com OSM, não substituindo, mas complementando suas informações, a segunda IES não aborda assuntos que coincidem, e a terceira IES não disponibiliza sua ementa.

Em uma IES foi encontrada a disciplina de Tópicos Especiais em Análise Organizacional, que faz referência a temas de OSM de uma forma geral, vale ressaltar que disciplinas de Tópicos são flexíveis com relação a conteúdo de um semestre para o outro.

Sete das IES apresentam nomes como: Organizações; Estruturas e Formatos Organizacionais/Análise de Sistemas Administrativos; Fundamentos da Administração I; Organizações; Sistemas, Estruturas e Gestão; Organizações: Sistemas, Estruturas e Gestão; Métodos Ágeis Em Operações; Gestão por Processos; Análise Organizacional, Sistemas e Métodos. Em duas IES, não foram encontradas a grade curricular e nem as ementas das disciplinas em seus websites.

Gráfico 01: OSM nas Universidades.

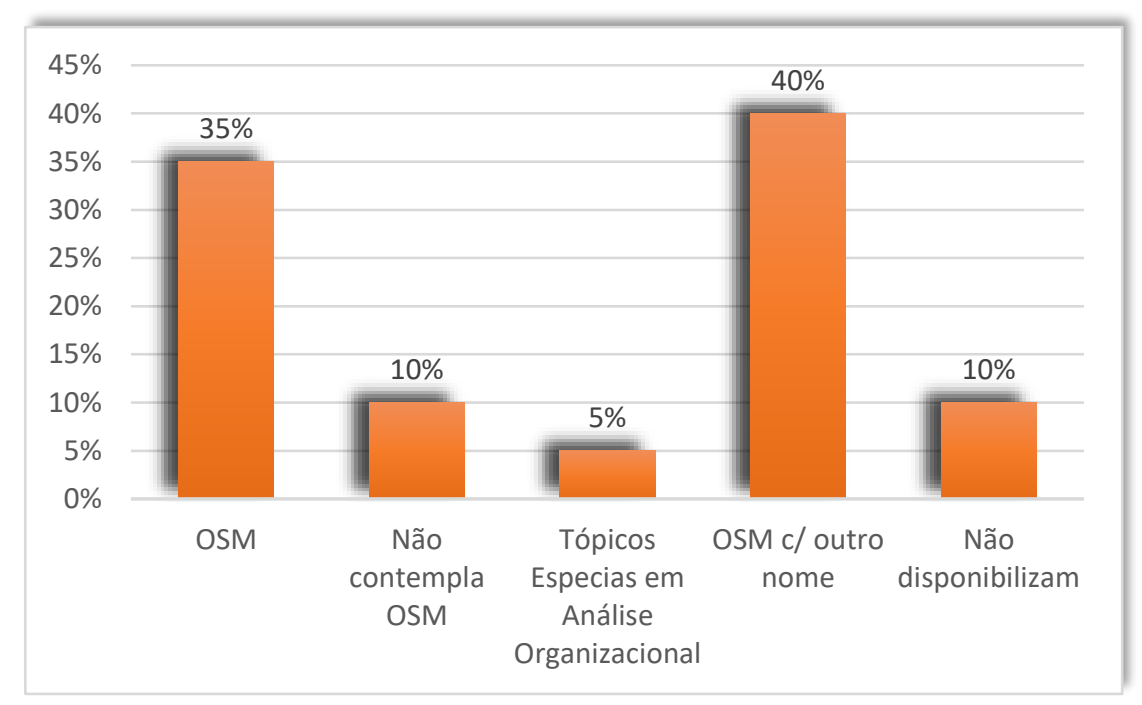

Fonte: Dados da pesquisa (2018).

Em concordância com Caldas (1999), nota-se claramente que não em todas, mas em boa parte dos cursos de Administração a disciplina tem sofrido poucas alterações, e que seu ensino é ainda fundamental na grade curricular do curso por seus conceitos e objetivos defendidos, estimulando a analisar o ambiente sócio organizacional.

Faz referência aos conteúdos programados na disciplina de OSM, o papel principal das organizações nas sociedades modernas, as causas que influenciam a vida organizacional, refletir 
sobre as organizações, a partir dos diferentes pontos de vista teóricos, avaliando os limites e vantagens de cada abordagem e analisar modelos, design e práticas organizacionais para ser capaz de fazer recomendações. Tais conteúdos vão de acordo com as ideias expostas por Oliveira (2013).

Compreende-se também que as IES que ainda usam o nome da disciplina como Organização de Sistemas e Métodos, usam abordagens semelhantes de acordo com a visão de Cardoso (2014), onde descreve que suas principais ferramentas estão relacionadas a tecnologias de ponta como fluxograma, planejamento de layout, o protocolo eletrônico.

Nesse sentido, pode-se constatar a veracidade na opinião de Cury (2006), quando apresenta que o foco da qualidade de gestão de processos se faz através das avaliações das ferramentas de OSM, onde seu trabalho auxilia no desenvolvimento de novas estratégias e avigoram a estrutura empresarial, introduzindo novas táticas que possibilitem o aumento da produtividade e eficiência das tarefas administrativas.

No quadro a seguir, apresentam-se as abordagens utilizadas nas IES em que as disciplinas exibem outra denominação na grade curricular.

Quadro 01: Disciplinas com outra nomenclatura.

\begin{tabular}{|c|l|}
\hline Nome da disciplina & \multicolumn{1}{|c|}{ Conteúdo programático } \\
\hline ORGANIZAÇÕES & $\begin{array}{l}\text { Esta disciplina tem por objetivos estimular o aluno a analisar o } \\
\text { ambiente sócio organizacional, o papel predominante das } \\
\text { organizações nas sociedades modernas e os fatores que } \\
\text { influenciam a vida organizacional; refletir sobre as } \\
\text { organizações, a partir de diferentes perspectivas teóricas, } \\
\text { avaliando os limites e vantagens de cada abordagem e analisar } \\
\text { modelos, design e práticas organizacionais para ser capaz de } \\
\text { fazer recomendações. }\end{array}$ \\
\hline ESTRUTURAS E FORMATOS & $\begin{array}{l}\text { Estruturas e formatos organizacionais como trabalhos juntos: } \\
\text { fundamentos, evolução e perspectivas teóricas sobre as } \\
\text { arquiteturas e os processos organizacionais. O modelo clássico } \\
\text { ARGANIZACIONAIS / }\end{array}$ \\
e as práticas convencionais de racionalização. A visão \\
contemporânea e as formais invocativas de organização. A \\
ênfase e alógica dos processos organizacionais.
\end{tabular}




\begin{tabular}{|c|c|}
\hline GESTÃO POR PROCESSOS & $\begin{array}{l}\text { Definição de processos e negócios de sua gestão. } \\
\text { Características dos novos processos. A importância do fluxo de } \\
\text { informação. Metas, clientes e fornecedores de processos. } \\
\text { Identificando a oportunidade de otimização de processos, } \\
\text { mapeamento de processos organizacionais. Fluxograma e } \\
\text { diagramas de processos. Tecnologia para a integração de } \\
\text { processos. Implementação de novos processos. Formulários } \\
\text { eletrônicos. Manuais. Analise e distribuição de trabalho e do } \\
\text { espaço físico. }\end{array}$ \\
\hline $\begin{array}{l}\text { ANÁLISE ORGANIZACIONAL, } \\
\text { SISTEMAS E MÉTODOS }\end{array}$ & $\begin{array}{l}\text { Fundamentos de organização, sistemas e métodos. Modelo } \\
\text { teórico das organizações: funções administrativas e } \\
\text { operacionais. Sistemas administrativos. Arquitetura } \\
\text { organizacional. Organização e reorganização. Estruturas } \\
\text { organizacionais. Mapeamento e análise de processos. Análise e } \\
\text { distribuição do trabalho. Gráficos de organização e controle } \\
\text { (fluxograma, Organograma etc). Manuais administrativos. } \\
\text { Formulários. Metodologias para levantamento. Análise e } \\
\text { Distribuição do Espaço (Layout). }\end{array}$ \\
\hline
\end{tabular}

Fonte: Dados da pesquisa (2018).

Nesse momento, quando se atenta para as IES que trabalham com outro título a disciplina, verifica-se que, apesar da alteração, o seu conteúdo planejado é conforme a das IES que permanecem inalteradas, pois apresentam, em sua grande maioria, programações de temas como a função da área, os principais componentes do sistema e as novas possibilidades de mudanças nos arranjos estruturais, como aponta Oliveira (2006).

Identifica-se a visão de Santos (2012), quando apresenta nos conteúdos programáticos uma junção com tecnologia para a integração de processos; funções administrativas e operacionais; análise das rotinas e distribuição do trabalho; alcance do controle; identificação das oportunidades de otimização de processos. Santos (2012) apresenta que OSM é composta por um campo vasto de conhecimento e é integrada a várias linhas de pensamentos.

Ainda conforme o Quadro 01, demostra-se a existência de assuntos acerca de estruturas e formatos organizacionais; departamentalização; descentralização e o estudo do layout; otimização de processos; mapeamento de processos organizacionais; Fluxograma e diagramas de processos; manuais administrativos; formulários; Metodologias para levantamento, dentre outros (CURY, 2013; OLIVIRA, 2013).

\section{Considerações Finais}

A pesquisa teve como objetivo verificar como as 20 IES melhores ranqueadas pelo MEC trabalham a disciplina de OSM no curso de Administração e quais as principais abordagens que 
são adotadas por elas, a verificação ocorreu-se através das ementas dos cursos de Administração e do PPC disponibilizados nos seus sites.

De acordo com a busca pelas ementas da disciplina de OSM, foi possível constatar que ainda se trabalha a disciplina com essa nomenclatura, também se observou em outros casos que a disciplina é trabalhada com outro título, o que pode apontar para onde se encaminha OSM, em poucos casos não se trabalha OSM.

Como considera Gontijo et al. (2015), a função de OSM tem sofrido transformações no decorrer dos tempos, demandando das organizações uma nova configuração diante da realidade e dos novos paradigmas. A abordagem temática das questões gerenciais, que conceituou a abertura das atividades de O\&M, deu lugar a um procedimento integrado, sistêmico.

Os principais assuntos abordados em ambas são Formatos e Estruturas organizacionais, análise de modelos, design e práticas organizacionais, departamentalização, centralização e descentralização, o estudo do layout, mapeamento de processos organizacionais, fluxograma e diagramas de processos.

Por fim, como pesquisas futuras. sugere-se que essa pesquisa seja feita com o maior número de IES ou até mesmo pesquisa com outras disciplinas, para saber não só para onde se encaminha OSM, mas para onde se encaminha o ensino da Administração.

\section{Referências}

ABDO, D. L.; SANTOS, L. R.; ARAUJO, L.; CAIXETA, M. A.; RODRIGUES, P. H. A; CARVALHO, W. A aprendizagem de logística, rh, osm, ética: opinião de administradores e graduandos sobre a metodologia de ensino. 2012. Disponível em: <http://www.fara.edu.br/sipe/index. php/anuario/article/viewFile/91/80>. Acesso em: 27 nov. 2018.

BRASIL. Lei n ${ }^{\circ}$ 9.394, de 20 de dezembro de 1996. Estabelece as diretrizes e bases da educação nacional. Disponível em: <http://legislacao.planalto.gov.br/legisla/legislacao. nsf/Viw_Identificacao/lei\%209.394-1996?OpenDocument>. Acesso em: 10 nov. 2018.

CALDAS, M. P. O triste destino da área de O\&M - I. RAE - Revista de Administração de EmpresasSão Paulo: Abr./Jun. 1999.

CALDAS, M. P. O que aconteceu com a área de O\&M? Pesquisa empírica sobre a evolução da função de organização e métodos no Brasil entre 1985 e 1997. XXII Encontro da ANPAD. Foz do Iguaçú / PR, setembro de 1998.

CARDOSO, C. P. Organizações, Sistemas e Métodos (OSM). 2014. Disponível em: <http://www.ufjf.br/oliveira_junior/files/2011/08/Aula-OSM-segundo-sem-2014.pdf>. Acesso em: 20 nov. 2018. 
CRUZ, T. Sistemas, organização \& métodos: estudo integrado orientado a processos de negócio sobre organizações e tecnologias da informação. Introdução à gerencia do conteúdo e do conhecimento / Tadeu Cruz - 4. ed. - São Paulo: Atlas, 2013.

CURY, A. Organização e métodos: uma visão holística / Antonio Cury. - 9. ed. - São Paulo : Atlas, 2017.

CURY, A. Organização e Métodos: uma visão holística. 8.ed. rev. e ampl. - 2. reimpr.- São Paulo: Atlas, 2006.

GONTIJO, F. E. K.; GESSNER, E.; FRAGA, B. D.; ARDIGO, J. D. A função do gestor de organização, sistemas e métodos na modelagem de processos para tecnologias da informação e comunicação. XXXV Encontro Nacional de Engenharia de Produção. Fortaleza, CE, Brasil, 13 a 16 de outubro de 2015.

OLIVEIRA, A. P. L.; BRANDÃO, E. N.; OLIVEIRA, E. L.; BRANDÃO, E. L. O; SILVA, P. T. S. Z. M: A importância da formação acadêmica para o administrador no desempenho de suas atividades profissionais. Anuário de Produções Acadêmico-científicas dos discentes da Faculdade Araguaia, [S.l.], v. 1, n. 1, abr. 2012. ISSN 2238-6378. Disponível em: <http://www.fara.edu.br/sipe/index.php/anuario/article/view/35>. Acesso em: 27 nov. 2018.

OLIVEIRA, D. P. R. Sistemas, Organização e Métodos: uma abordagem gerencial. 16.ed. São Paulo: Atlas, 2006.

REITZ, S. J: A importância do estudo da disciplina de OSM para o acadêmico, futuro administrador, março de 2014. Disponível em: <http://www.administradores.com.br/artigos/academico/a-importanciado-estudo-da-disciplina-de-osm-para-o-academico-futuro-administrador/76196/>. Acesso em: 28 out. 2018.

SANTOS, L. Organização de sistemas e métodos. 2012. Disponível em: $<$ https://scholar.googleusercontent.com/scholar?q=cache:XxzqxQymgAJ:scholar.google.com/+osm+d efini\%C3\%A7\%C3\%B5es\&hl=pt-BR\&as_sdt=0,5>. Acesso em: 21 out. 2018.

SILVA, A. M; SILVA. A, S. B: A Organização, Sistemas e Métodos: um estudo acerca de sua aplicabilidade em uma empresa do setor de saúde. XIII SEGeT. Resende, RJ, out/nov de 2016.

SILVA, M. das G. da. Metodologia científica. Centro de Ciências Sociais e Educação da Universidade do Estado do Para. 2008. Disponível em: https://www.unifra.br/professores /13732/ARTIGO\%20\%2030\%20DE\%20MAR\%C3\%87O.pdf. Acesso em: 23 maio 2018.

\section{Como citar este artigo (Formato ABNT):}

BARROS, Andreza Raquel Campos; OLIVEIRA, Alyne Leite de; LIMA, Antonio Raniel Silva. Para Onde Caminha a Disciplina de Organização, Sistemas e Métodos nos Cursos de Administração: uma Análise Documental. Id on Line Rev.Mult. Psic., 2019, vol.13, n.43, p. 733-747. ISSN: 1981-1179.

Recebido: 27/11/2018;

Aceito: 01/12/2018 